\title{
Ressemantização das áreas centrais das cidades brasileiras e mercado imobiliário habitacional: o caso recifense (Brasil)
}

\author{
Re-semantization of the central areas of Brazilian cities \\ and the residential real estate market: the case of Recife (Brazil)
}

Norma Lacerda [I] Iana Ludermir Bernardino [II]

\begin{abstract}
Resumo
Na década de 1990, as baixas taxas de crescimento da economia brasileira e sua inserção no mundo globalizado tiveram repercussões sobre os centros históricos das grandes cidades ao impulsionarem os governos locais a neles investirem para atrair empresas. Isso tem significado a volta do interesse do capital por esses centros e a revalorização dos respectivos entornos mediante empreendimentos imobiliários habitacionais. Ante essa dinâmica, 0 objetivo deste texto é identificar as implicações do retorno dos investimentos aos centros históricos sobre o mercado imobiliário de unidades habitacionais antigas e sobre o mercado de moradias novas no seu entorno, responsável pela criação de novas espacialidades que pouco se articulam às antigas espacialidades, tendo como objeto de reflexão a área central recifense.
\end{abstract}

Palavras-chave: áreas centrais; centros históricos; mercado imobiliário habitacional.

\begin{abstract}
In the 1990s, the low growth rates of the Brazilian economy, along with the country's insertion in the globalized world, had repercussions on the historic centers of large cities, since local governments were driven to invest in these areas in order to attract private companies. Due to this, private capital has returned to these centers, which has led to the revaluation of their respective surroundings by means of housing real estate developments. In view of this dynamics, this paper aims to identify the implications of the return of investments in historic centers for the real estate market of old housing units and for the market of new dwellings in their surroundings, responsible for the creation of new spatialities that are poorly articulated to the old ones. Our object of study is the central area of the city of Recife.
\end{abstract}

Keywords: central areas; historic city centers; residential real estate market. 


\section{Introduzindo o debate}

Há algum tempo, a literatura tem denunciado o retorno do interesse do capital pelas áreas centrais. No caso brasileiro, esse retorno vem acontecendo, sobretudo a partir dos anos 2000, sob o respaldo do paradigma do empreendedorismo urbano e fortemente impulsionado por políticas públicas de incentivo financeiro/fiscal e de dotação/recuperação de infraestruturas. Essas políticas de renovação urbana surgem como estratégia de ressemantização de espacialidades existentes com o intuito de vendê-las como novos produtos urbanos.

O caso do Centro Histórico do Recife (CHR) - formado pelos bairros do Recife, Santo Antônio e partes dos de São José, Boa Vista e Soledade - é paradigmático. Na primeira metade dos anos 1980, diante de um panorama de evasão habitacional e de migração das atividades de maior prestígio para outras localidades, começaram a ser formulados programas para a recuperação de partes do seu território. A recuperação do bairro do Recife, iniciada nos anos 1990, ganhou impulso com a implantação, a partir do ano 2000, do Projeto Porto Digital. Esse projeto visa à estruturação da área para a atração de empresas de tecnologia da comunicação e informação (TIC) e de economia criativa (EC), por meio da dotação de implantação/recuperação de infraestruturas, fortes incentivos fiscais (redução de $60 \%$ do Imposto sobre Serviços - ISS), da cessão, por parte do governo do estado de Pernambuco, de espaços construídos a essas empresas e da aquisição de imóveis pelo Núcleo Gestor do Porto Digital. "O Parque é tema frequente de matérias publicadas na imprensa local, ressaltando seus avanços: [...] os 315 empreendimentos 'embarcados', 9 mil empregos gerados e o faturamento da ordem de R\$ 2 bilhões alcançados em 2018" (Fernandes e Lacerda, 2019). Pouco depois do início do Porto Digital, financiamentos federais ${ }^{1}$ foram disponibilizados para a reabilitação de monumentos históricos de potencialidade turística por meio do Programa Monumenta.

Além dessa dinâmica, distinguem-se duas outras protagonizadas por uma conjuntura macroeconômica favorável. Uma delas diz respeito à potencialidade, ainda no bairro do Recife, para a localização de equipamentos e serviços. Nesse quesito, por meio do Projeto Porto Novo, antigos armazéns foram recuperados de forma a abrigar lojas, bares e restaurantes, escritórios, cinemas, museu, centro de convenções e terminal marítimo de passageiros. Para a viabilização do Projeto, o porto do Recife arrendou a um consórcio de empresas uma larga faixa de terrenos, incluindo os armazéns. Em 2018, foi aprovado, no âmbito da Prefeitura do Recife, o Projeto de Recuperação do Antigo Moinho Recife, também situado no aludido bairro. Trata-se de um complexo multiuso, formado por edificações destinadas a hotel, flats, convenções e usos complementares, como bares, cafés, restaurantes, galeria de arte, lojas, rooftop e outros.

A outra dinâmica de revalorização refere-se à redescoberta da área central pelo setor privado educacional de ensinos técnico e superior, fortemente impulsionado pelas políticas públicas de incentivo à educação e à capacitação vigentes no período dos governos Lula (2002-2009) e Dilma (2010-2016). 0 bairro de Santo Antônio - caracterizado, até a década de 2000 , pela presença marcante de edificações parcialmente esvaziadas - vem 
sendo palco da implantação de centros acadêmicos e começa a se caracterizar pela concentração de equipamentos educacionais. Já, nos bairros de São José, Boa Vista e Soledade, onde ainda persiste a função habitacional, são mais escassos os incentivos à implantação de atividades e serviços especializados e é marcante o quadro de degradação.

Ao contrário do centro histórico do Recife, o seu entorno não é regido por restrições à mudança do padrão de ocupação. Nele tem surgido empreendimentos imobiliários verticais, direcionados às classes de rendimentos médio e alto, que remetem à criação de novas espacialidades residenciais. Tal dinâmica resulta, no âmbito nacional, de uma conjuntura favorável à produção de novas moradias, instaurada em consequência da disponibilização de crédito a produtores e consumidores, notadamente a partir dos anos 2000 e acentuada com o lançamento do pacote habitacional Minha Casa Minha Vida, em 2009. No contexto local, a conjuntura favorável é resultante (1) da geração de empregos qualificados no CHR, decorrentes das dinâmicas econômicas acima referidas; (2) da excessiva valorização do solo em outras partes da cidade, o que tem levado a promoção imobiliária a buscar novas áreas para os seus investimentos, sobretudo, as situadas nas frentes d'água; e (3) da imobilidade urbana, ocasionada pelas dificuldades de deslocamento das pessoas.

Tudo isso tem valorizado o entorno do $\mathrm{CHR}$, enquanto área de grande potencial de exploração, conformando uma "nova fronteira" de valorização do capital no Recife. Nesse contexto, não é de se estranhar a presença, nesse entorno, de empreendimentos habitacionais e também comerciais e de serviços (call centers, sede da Rede Globo no Recife e, mais recentemente, delicatéssens, bares, restaurantes, etc.). Guardando as devidas especificidades, essa dinâmica tem marcado presença em outras áreas centrais, a exemplo de Belém, São Luís e Salvador.

Tais constatações instigaram a formulação do objetivo deste texto: analisar - a partir do caso recifense - a dinâmica de ressemantização de áreas urbanas centrais (centros históricos e entornos) para mostrar que o mercado de imóveis antigos, situados nesses centros, pouco se articula à dinâmica de produção de novas espacialidades residenciais nos seus respectivos entornos, o que resulta em mercados diferentes com baixo nível de comparabilidade.

Atingir esse objetivo exigiu, inicialmente, revelar - por meio dos dados dos Censos de 2001 e 2010 - a persistência do mercado habitacional no CHR, especificamente o de aluguel, mesmo diante da ausência de uma política habitacional para esse centro. Em seguida, requereu apontar como vem se dando a recente dinâmica espacial dos investimentos imobiliários residenciais no território recifense, direcionados ao mercado de compra e venda, mostrando que, durante um largo período (dos anos 1970 aos anos 2000), correspondente praticamente ao período de degradação do CHR, o seu entorno foi "desprezado" pelo setor imobiliário habitacional, e também evidenciando que, nos últimos anos, esse mesmo entorno vem se conformando como uma "nova fronteira" de expansão do setor imobiliário. Na sequência, foi necessário, por meio de uma revisão/complementação das reflexões teóricas já realizadas pelas autoras do presente artigo, realçar as distinções de funcionamento do mercado imobiliário residencial no $\mathrm{CHR}$, marcado pela presença significativa de imóveis alugados, no confronto com o mercado 
habitacional de compra e venda de unidades novas localizadas no seu entorno. Isso permitiu concluir que, embora esses dois mercados participem do processo de ressignificação da área central recifense, trata-se de mercados com diferentes mecanismos de funcionamento.

\section{Mercado habitacional de aluguel: importante meio de acesso à moradia no Centro Histórico do Recife}

\begin{abstract}
A área central do Recife - composta pelo seu centro histórico e pelo seu entorno - exerce hoje uma função de centralidade urbana funcional e de centralidade histórica superlativa, contendo o mais largo espectro de tempos históricos dessa cidade representados nas suas edificações. Essa área central pode ser considerada, então, um mosaico urbano composto por diversos padrões de ocupação, característicos de períodos específicos e sobre os quais incidem normativas urbanísticas diversas.
\end{abstract}

Dito isso, cabe, desde já, situar o leitor, por meio da Figura 1, quanto à localização do Centro Histórico do Recife em relação à cidade, além de nominar os bairros e as partes de bairros que o compõem, bem como a área delimitada como o seu entorno.

Importa anotar que as dinâmicas espaciais que vêm ocorrendo no CHR e seu entorno são regidas pelo mercado imobiliário, formado por submercados consoante os seguintes elementos de diferenciação: (1) imóveis novos ou secundários (procedentes de ciclos produtivos anteriores); (2) destinados a usos residenciais ou comerciais e de serviços (funcionalidades); e (3) para serem alugados ou vendidos (tipo de transação). Como o interesse deste texto é o mercado habitacional em áreas centrais (centros históricos e entornos), a primeira tarefa foi verificar, considerando-se todas as combinações possíveis referentes ao uso habitacional, quais são as que mais chamaram a atenção nessas áreas. Aplicando a análise combinatória aos 3 elementos de diferenciação acima aludidos, têm-se 8 tipos de mercados, dos quais 4 se referem ao uso habitacional: imóveis residenciais novos para compra e venda, imóveis residenciais novos para aluguel, imóveis residenciais usados para compra e venda e imóveis residenciais usados para aluguel.

Com o intuito de mostrar a importância do mercado habitacional de aluguel como importante meio de acesso à moradia no $\mathrm{CHR}$, cabe destacar que, em 1991, 51,6\% dos domicílios particulares permanentes localizados no CHR eram alugados (Tabela 1), passando a representar, em 2010, 46,1\% dos domicílios (fortemente concentrados no bairro da Boa Vista). Uma redução não significativa, porquanto quase 20 anos separam os censos aqui considerados. Tal redução, provavelmente, revela a mudança de uso habitacional para o comercial. De qualquer forma, os dados apontam que a locação constitui uma importante forma de acesso à moradia nesse centro. Na cidade do Recife, a relação era, em 2010, de 22,2\% de domicílios alugados, e os domicílios próprios representavam $73,1 \%$.

Com certeza, para essa elevada participação dos domicílios próprios no Recife, muito contribuíram os financiamentos habitacionais - notadamente os concedidos pelo BNH (1964-1986) e pelo Programa Minha Casa Minha (a partir de 2009) -, o que viabilizou transações de compra e venda de unidades habitacionais. Afinal, a produção de habitações 
Figura 1 - Área central do Recife (RPA1) e Centro Histórico do Recife - 2018

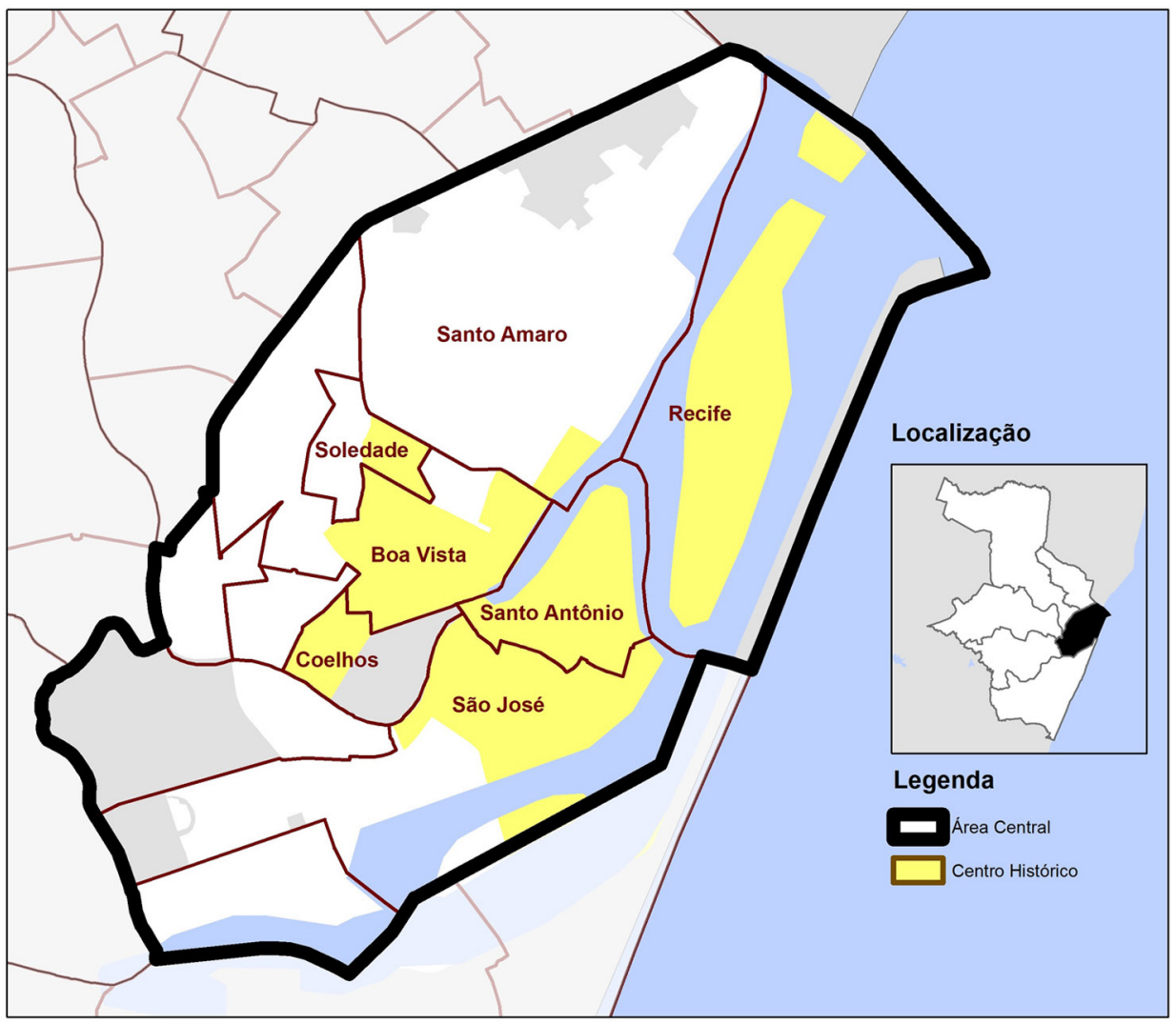

Fonte: elaboração própria.

novas pelo setor imobiliário é essencialmente destinada ao mercado de compra e venda. A representatividade dos domicílios alugados nas áreas históricas especificamente e na área central como um todo, onde o estoque edificado é relativamente antigo, pode, ao contrário, denotar que, quando se trata de imóveis oriundos de ciclos precedentes, existe uma significativa representatividade do regime de ocupação de aluguel nessas áreas.
O aludido mercado de locação oferece moradias usadas bastante diferenciadas, e o seu funcionamento é determinado pelo comportamento dos seus inúmeros agentes, notadamente dos proprietários/locadores e dos inquilinos. Tais questões serão aprofundadas quando do confronto dos mecanismos de funcionamento do mercado de aluguel de unidades antigas com os do mercado de unidades novas. 
Tabela 1 - Evolução da Condição de Ocupação

dos Domicílios Particulares Permanentes (DPP) no CHR (1991-2010)

\begin{tabular}{|c|c|c|c|c|c|c|c|c|}
\hline \multirow{2}{*}{\multicolumn{3}{|c|}{ Condição de Ocupação DPP }} & \multicolumn{5}{|c|}{ CHR } & \multirow{3}{*}{$\begin{array}{c}\text { Recife } \\
305.901,0\end{array}$} \\
\hline & & & \multirow{2}{*}{$\begin{array}{r}\text { Recife } \\
130,0\end{array}$} & \multirow{2}{*}{$\begin{array}{c}\begin{array}{c}\text { Santo } \\
\text { Antonio }\end{array} \\
132,0\end{array}$} & \multirow{2}{*}{$\begin{array}{c}\text { São José* } \\
531,0\end{array}$} & \multirow{2}{*}{$\begin{array}{c}\text { Boa Vista* } \\
3.332,0\end{array}$} & \multirow{2}{*}{$\begin{array}{c}\text { Total } \\
4.125,0\end{array}$} & \\
\hline \multirow{10}{*}{1991} & \multirow{2}{*}{ Total } & V. Abs. & & & & & & \\
\hline & & $\%$ & 100,0 & 100,0 & 100,0 & 100,0 & 100,0 & 100,0 \\
\hline & \multirow{2}{*}{ Próprios } & V. Abs. & 122,0 & 33,0 & 251,0 & $1.416,0$ & $1.822,0$ & $227.601,0$ \\
\hline & & $\%$ & 93,8 & 25,0 & 47,3 & 42,5 & 44,2 & 74,4 \\
\hline & \multirow{2}{*}{ Alugados } & V. Abs. & 5,0 & 84,0 & 252,0 & $1.786,0$ & $2.127,0$ & $62.427,0$ \\
\hline & & $\%$ & 3,8 & 63,6 & 47,5 & 53,6 & 51,6 & 20,4 \\
\hline & \multirow{2}{*}{ Cedidos } & V. Abs. & 3,0 & 14,0 & 28,0 & 116,0 & 161,0 & $13.591,0$ \\
\hline & & $\%$ & 2,3 & 10,6 & 5,3 & 3,5 & 3,9 & 4,4 \\
\hline & \multirow{2}{*}{ Outros } & V. Abs. & - & 1,0 & - & 14,0 & 15,0 & $2.282,0$ \\
\hline & & $\%$ & - & 0,8 & - & 0,4 & 0,4 & 0,7 \\
\hline \multirow{10}{*}{2010} & \multirow{2}{*}{ Total } & V. Abs. & $x$ & 142,0 & 649,0 & $3.936,0$ & $4.727,0$ & $470.470,0$ \\
\hline & & $\%$ & $x$ & 100,0 & 100,0 & 100,0 & 100,0 & 100,0 \\
\hline & \multirow{2}{*}{ Próprios } & V. Abs. & $x$ & 65,0 & 344,0 & $1.972,0$ & $2.381,0$ & $343.914,0$ \\
\hline & & $\%$ & $x$ & 45,8 & 53,0 & 50,1 & 50,4 & 73,1 \\
\hline & \multirow{2}{*}{ Alugados } & V. Abs. & $x$ & 73,0 & 286,0 & $1.822,0$ & $2.181,0$ & $104.621,0$ \\
\hline & & $\%$ & $x$ & 51,4 & 44,1 & 46,3 & 46,1 & 22,2 \\
\hline & \multirow{2}{*}{ Cedidos } & V. Abs. & $x$ & 4,0 & 14,0 & 126,0 & 144,0 & $18.606,0$ \\
\hline & & $\%$ & $x$ & 2,8 & 2,2 & 3,2 & 3,0 & 4,0 \\
\hline & \multirow{2}{*}{ Outros } & V. Abs. & $x$ & - & 5,0 & 16,0 & 21,0 & $3.329,0$ \\
\hline & & $\%$ & $x$ & - & 0,8 & 0,4 & 0,4 & 0,7 \\
\hline
\end{tabular}

Fonte: Censos Demográficos do IBGE de 1991 e 2010.

Observação: O Censo do IBGE de 2010 não fornece os dados acerca da condição de ocupação dos DPPs

para os setores censitários que compõem o bairro do Recife.

* Nota: os dados dos bairros de São José e da Boa Vista referem-se às partes incluídas no perímetro do CHR. 


\section{Mercado de novas unidades habitacionais no entorno do centro histórico}

Atualmente, a configuração urbana e as normativas legais que regem a produção do ambiente construído no entorno do CHR permitem que parte considerável do seu território seja propício à transformação dos padrões de ocupação e à atuação imobiliária para a produção de novos imóveis. Embora a área central recifense contenha Zonas Especiais de Preservação do Patrimônio Histórico-Cultural - ZEPHs (Figura 2), assim como áreas pobres classificadas como Zonas Especiais de Interesse Social - Zeis, onde são relativamente limitadas as possibilidades de transformação, quase a metade do seu território - aqui denominado entorno do centro histórico (em branco) - pode abrigar novos ciclos de produção de imóveis.

Figura 2 - Área central recifense: zonas especiais - 2018

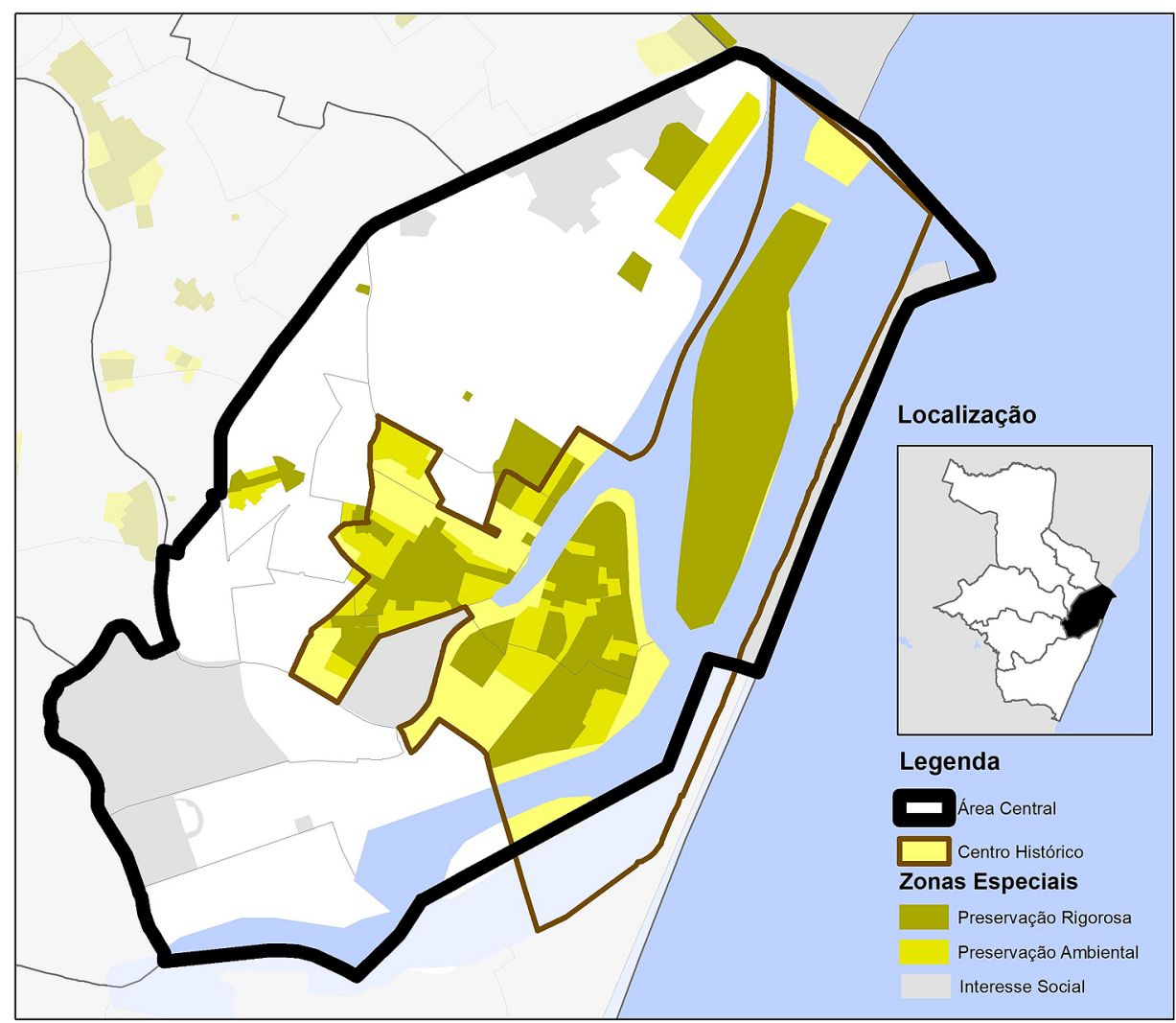

Fonte: Bernardino (2018). 
Apesar da presença relativamente marcante de ZEPHs, onde são limitadas as possibilidades de atuação capitalista para produção de novas espacialidades residenciais, existem hoje nessa área central recifense - correspondente à Região Política Administrativa 1 (RPA1) 107,97 hectares referentes à soma de lotes classificados como terrenos, galpões e postos de gasolina (Tabela 2). Esses lotes, na maioria das vezes, são enxergados como terrenos com grande potencial de reconversão (mudança de uso e mudança do padrão de ocupação). Esse montante, em confronto com o potencial de reconversão do Recife como um todo $(639,45$ ha), representa $16,88 \%$. Isso sem contar com remembramentos de terrenos, possibilidade respaldada pela legislação urbanística vigente. ${ }^{2}$

Os lotes relativamente favoráveis às intervenções na RPA1 possuem localizações e dimensões variadas, mas é notável a existência de lotes e de glebas de grandes extensões situados nas frentes d'água (Figura 3). Há, ainda, aqueles lotes que, mesmo relativamente distantes das frentes d'água, podem abrigar novos imóveis verticalizados com "vista definitiva", já que o que os aparta da vista privilegiada para o horizonte são zonas históricas com gabarito das edificações praticamente estável.

O contraste entre as áreas com notáveis incentivos à produção de novos imóveis verticalizados, com coeficientes de aproveitamento do terreno superiores a outras partes da cidade e sem limites de gabarito, e aquelas áreas reconhecidas institucionalmente como ZEPHs tem permitido que imóveis novos de edificações multifamiliares verticalizadas se avizinhem e se contraponham às antigas espacialidades residenciais presentes nessas zonas históricas, como demonstra a Figura 4.

Diante de uma conjuntura relativamente favorável à produção de novas espacialidades residenciais - caracterizada pela disponibilidade de crédito para a produção e a comercialização de imóveis -, a área central recifense passou a atrair o interesse do setor imobiliário para a produção de novos imóveis residenciais nessa última década (2008-2018). Essa dinâmica de revalorização da centralidade urbana (CHR e entorno) recifense esteve calcada, objetivamente, em investimentos em infraestrutura, estímulos fiscais à instalação de atividades de TIC, EC e educação e parâmetros

Tabela 2 - Recife: áreas dos lotes (hectares) com potencial de transformação por RPA

\begin{tabular}{l|c|c|c|c|c|c|c}
\hline \multicolumn{1}{c|}{ Localidade/Áreas } & RPA 1 & RPA 2 & RPA 3 & RPA 4 & RPA 5 & RPA 6 & Recife \\
\hline $\begin{array}{l}\text { Soma das áreas dos lotes } \\
\begin{array}{l}\text { com potencial de transformação } \\
\text { (valores absolutos) }\end{array}\end{array}$ & 107,97 & 6,75 & 52,86 & 334,93 & 42,33 & 94,62 & 639,45 \\
\hline $\begin{array}{l}\text { Soma das áreas dos lotes } \\
\text { com potencial de transformação } \\
\text { (percentuais) }\end{array}$ & $16,88 \%$ & $1,06 \%$ & $8,27 \%$ & $52,38 \%$ & $6,62 \%$ & $14,80 \%$ & $100,00 \%$ \\
\hline
\end{tabular}

Fonte: Bernardino (2018). 
Figura 3 - Área central recifense: lotes com potencial de transformação imobiliária - 2018

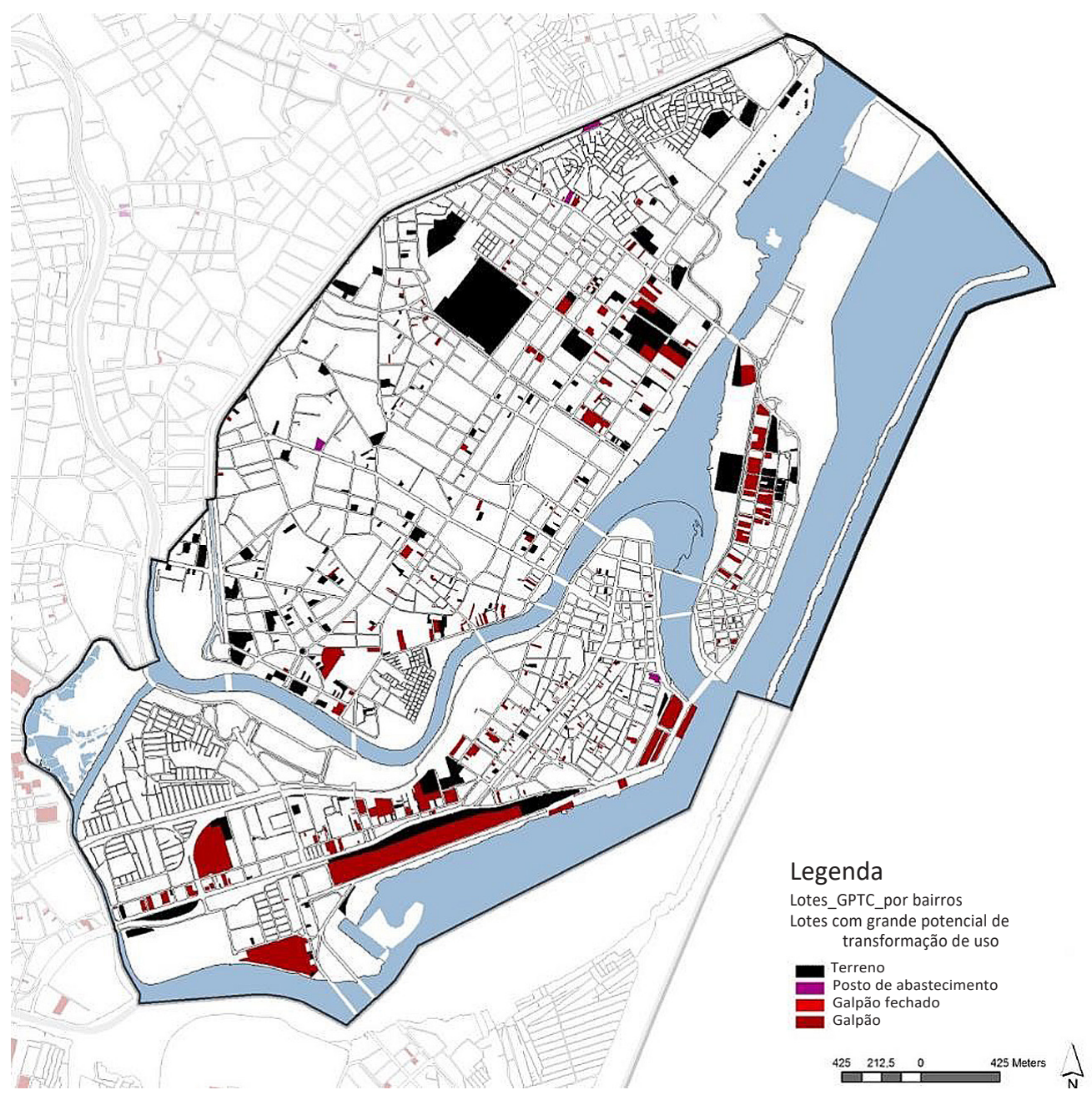

Fonte: Bernardino (2018).

urbanísticos favoráveis à densidade e à verticalização. Subjetivamente, tem surgido no imaginário das classes média e alta como "área habitacional ideal", destinada aos mais diversos perfis familiares dada à proximidade aos postos de trabalho - o que tende a minimizar o dispêndio de tempo e de recursos com os deslocamentos rotineiros - e à possibilidade de vivenciar a história e de estar "perto de tudo", como denotam alguns anúncios publicitários para a promoção de imóveis residenciais nela localizados (Bernardino, 2018). Significa isso que foi socialmente construída uma nova convenção urbana, pautada no compartilhamento de crenças que envolve um conjunto de participantes do mercado (Abramo, 2007). 
Figura 4 - Área central do Recife: sequência gráfica ilustrativa das espacialidades residenciais -2018

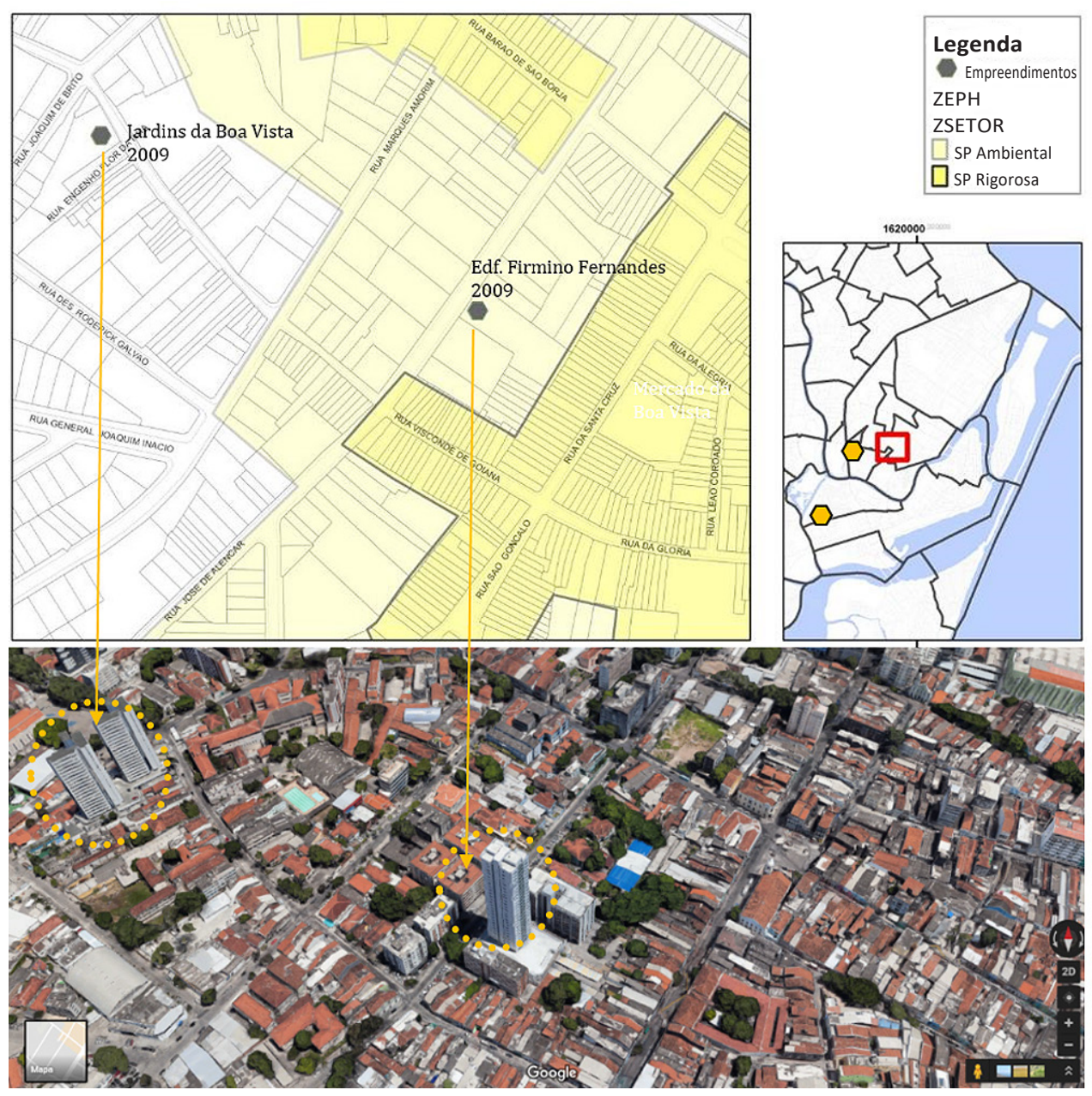

Fonte: Bernardino (2018).

Como resultado da "redescoberta" dessa área central pelo setor imobiliário habitacional, houve uma crescente participação relativa da RPA1 do Recife nas transações de compra e venda nos lançamentos imobiliários da cidade. Até meados da década de 2000, era inexpressiva a participação dessa região no total das transações e dos lançamentos na cidade, situação que se alterou ao ponto de, em 2014, ser a RPA1 responsável por 24\% dos imóveis transacionados na cidade, conforme demonstra o Gráfico 1. 
Gráfico 1 - Unidades habitacionais vendidas por região no Recife de 2000 a 2014

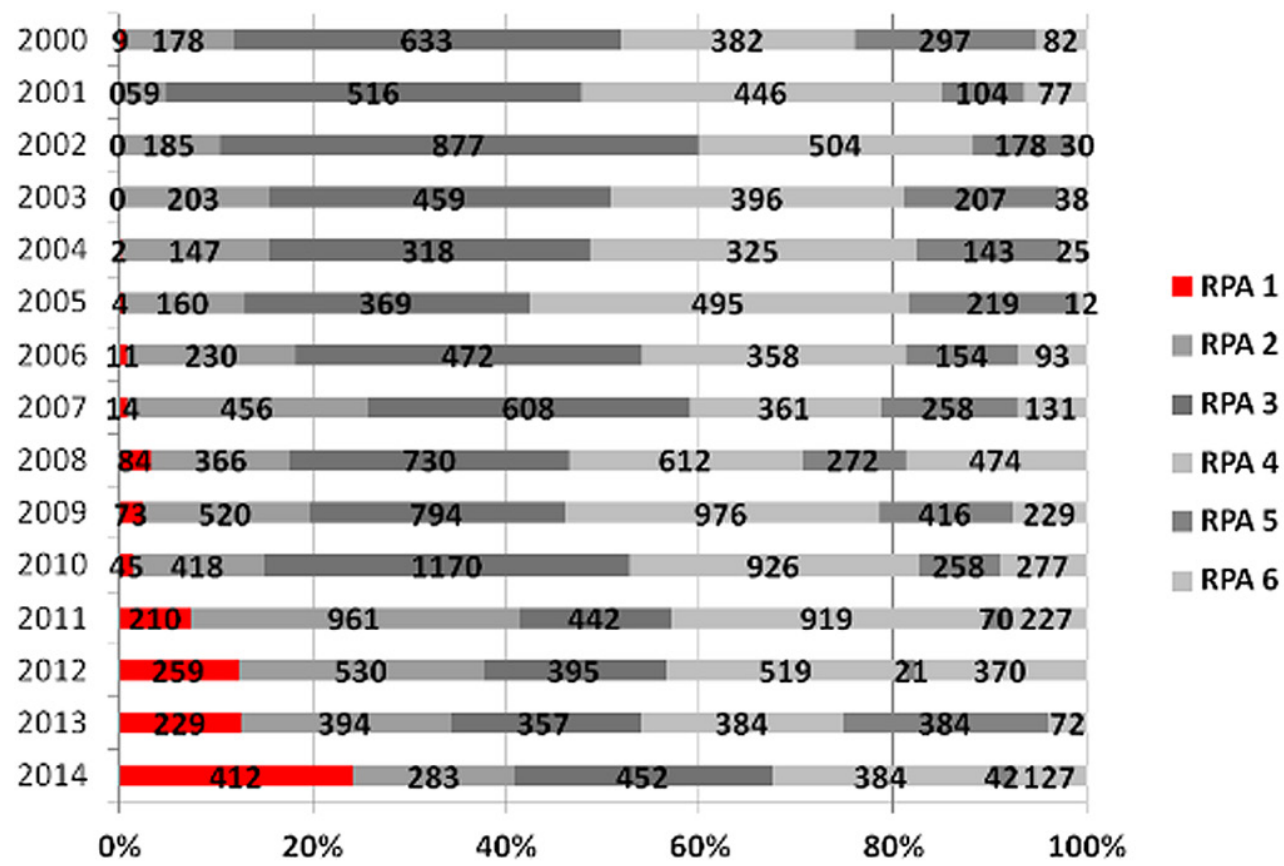

Fonte: Índice de Velocidade de Vendas 2000 - 2014. Ademi/Fiepe, apud Bernardino (2018).

Entre 2008 e 2018, os novos empreendimentos residenciais finalizados, ${ }^{3}$ lançados e em obras representam um acréscimo de 2.845 novas unidades habitacionais à área central tradicional recifense. Tendo em vista que a Região apresentava em 2010, segundo o Censo Demográfico do IBGE, 29.256 domicílios, as novas unidades habitacionais representam um crescimento relativo de 9,72\% no número de domicílios no período de uma década. As novas moradias poderiam abrigar, aproximadamente, 7.600 novos residentes $^{4}$ nessa região que, entre 2000 e 2010, não teve praticamente nenhum crescimento na sua população residente. ${ }^{5}$ Considerando os empreendimentos em fase de análise pela 
prefeitura do Recife, com vista à obtenção de alvará de construção, deverão ser acrescidas, ainda, 1.076 unidades ao número de novas residências que figurarão na área central a médio prazo, tendo-se um total de 3.921 novos domicílios do tipo apartamento em edifícios verticais multifamiliares.

A espacialização de alguns dos empreendimentos que servem ao cômputo do número dessas unidades habitacionais é demonstrada na Figura 5, na qual se visualizam as ZEPHs que compõem o Centro Histórico do Recife e se distinguem os empreendimentos finalizados, lançados e em obras daqueles que estão meramente anunciados, ainda em tramitação de aprovação.

A partir do levantamento e mapeamento de todos os imóveis residenciais construídos nos últimos doze anos ${ }^{6}$ e situados no entorno do Centro Histórico do Recife, foi possível

Figura 5 - Área central do Recife: empreendimentos finalizados, em obras e anunciados -2018

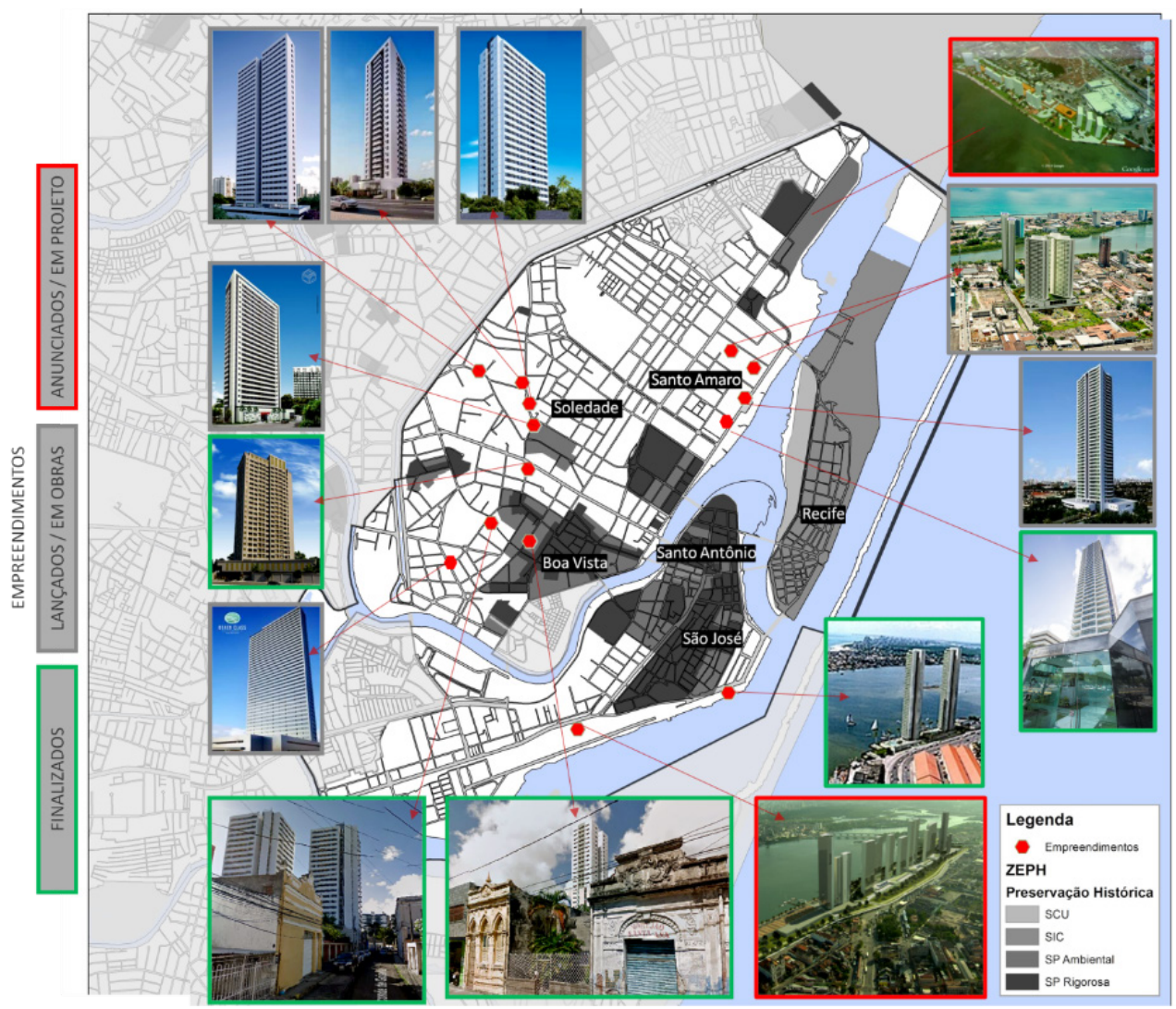

Fonte: Bernardino (2018). 
identificar as empresas responsáveis pelos empreendimentos. São sete as empresas com atuação nesse entorno, além de um grupo e de um consórcio de empresas, ${ }^{7}$ sendo este último criado para viabilizar um empreendimento específico, totalizando nove figuras jurídicas. As sete empresas em questão se comportam como incorporadoras/construtoras, chegando a comercializar diretamente as novas unidades habitacionais. Sediadas no Recife, ${ }^{8}$ tais empresas estão consolidadas, tendo de 30 a 65 anos de atuação no mercado local. Já o grupo e o consórcio são responsáveis, cada um deles, por um grande empreendimento que se encontra em fase de análise pela prefeitura do Recife. Por isso, esses empreendimentos ainda não foram construídos.

O levantamento realizado permitiu também identificar a representatividade de cada uma das empresas no total das 3.921 novas

Tabela 3 - Área central recifense: unidades habitacionais construídas e lançadas por construtora (2009 a 2017)

\begin{tabular}{l|c}
\hline \multicolumn{1}{c|}{ Construtora/Incorporadora } & Número de UHs \\
\hline Moura Dubeux & 1.368 \\
Conic & 306 \\
Duarte & 268 \\
Pernambuco Construtora & 108 \\
Conlar & 192 \\
L Priori & 220 \\
Nassau & 100 \\
Grupo JCPM & 283 \\
Consórcio Novo Recife & 1.076 \\
\hline Total & 3.921 \\
\hline
\end{tabular}

Fonte: Bernardino (2018). unidades habitacionais construídas e propostas no referido período, como é possível observar na Tabela 3 e no Gráfico 2.

Embora variadas empresas participem da dinâmica de produção imobiliária na área central, a atuação de uma empresa em particular, a Moura Dubeux, dada a sua participação também no Consórcio Novo Recife, está relacionada a $62 \%$ das novas unidades construídas e/ou planejadas para a área central do Recife, enquanto a atuação das outras sete empresas combinadas resultou em $38 \%$ das unidades habitacionais computadas.

Ainda que parte das unidades habitacionais acima computadas não seja passível de comercialização, ${ }^{9}$ é possível afirmar que, na área central recifense, aproximadamente 2.845 unidades habitacionais foram produzidas enquanto bens primários e disponibilizadas, ${ }^{10}$ como tal, no mercado de compra e venda. No caso,

Gráfico 2 - Área central recifense: unidades habitacionais construídas e lançadas por construtora (2009 a 2017)

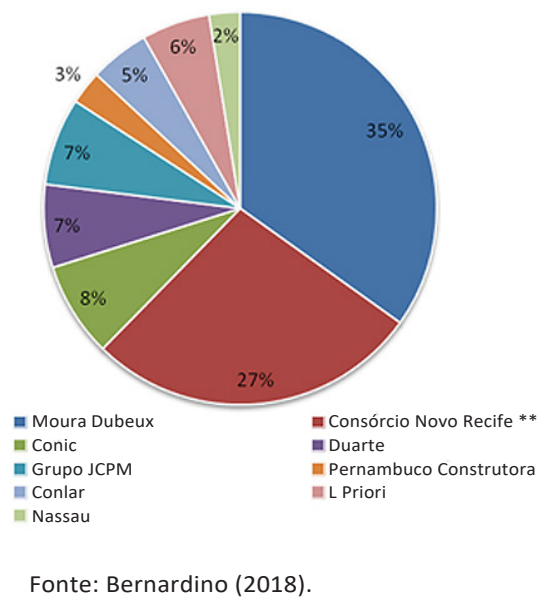


trata-se de unidades do tipo apartamento em edifício multifamiliar de 20 a 47 pavimentos, o que indica uma certa homogeneização das mercadorias produzidas e transacionadas no âmbito desse mercado.

Diante das evidências assinaladas até então, no decorrer deste artigo, e considerando que elas estão também presentes - guardando as suas particularidades - em outras áreas centrais das cidades brasileiras, apresentam-se, a seguir, as mais relevantes distinções entre o mercado imobiliário em centros históricos, nos quais predominam as transações de aluguel, e o mercado imobiliário de novas unidades no seu entorno, no qual predominam as transações de compra e venda.

\section{Mercado imobiliário habitacional de locação nos centros históricos versus mercado de novas moradias no seu entorno}

No sentido de entender os fundamentos da recente dinâmica habitacional nas áreas centrais das cidades brasileiras, considera-se importante entender as diferentes relações mercadológicas que possam se dar no âmbito dos centros históricos - nos imóveis entendidos como antigas espacialidades residenciais - e no seu entorno, nos novos imóveis - entendidos como novas espacialidades residenciais -, produzidas a partir de um recente novo ciclo de produção capitalista de espaços residenciais e que fazem referência a uma parcela relativamente pequena dos imóveis.

Lacerda (1993) chama a atenção - quando se pretende apreender os mecanismos referentes ao funcionamento de um mercado e, em extensão, à fixação dos preços nele praticados - para a imprescindibilidade de se identificar o modelo segundo o qual os agentes tomam as suas decisões. Significa isso desvendar se o mercado em análise funciona a partir de um modelo de concorrência perfeita ou de concorrência imperfeita. Sendo de concorrência imperfeita, importa esclarecer se assume predominantemente as características de concorrência monopolista, monopólio ou oligopólio. Isso exige identificar (1) as características dos bens transacionados (homogêneos ou heterogêneos), (2) a quantidade de agentes atuantes na oferta e na demanda, (3) os seus respectivos graus de informação e formas de comportamentos e (4) a capacidade dos ofertantes de introduzir inovações, quer seja tecnológica, organizacional ou de produtos.

No caso do mercado imobiliário habitacional nos centros históricos, os produtos são materialmente diversos, quanto ao tipo (sobrado, casa, apartamento, cômodo), ao tamanho, ao material de construção, ao estado de conservação e, por óbvio, à localização dos imóveis. Nesse mercado, comercializam-se imóveis grandes e pequenos, em ruína ou em excelente nível de conservação. São comprados imóveis habitacionais mais novos (poucos) e imóveis seculares. Trata-se, portanto, de um mercado de produtos fortemente heterogêneos, bem distinto do mercado de imóveis habitacionais novos, no qual, evidentemente, existem diferenciações menos acentuadas. Essas diferenciações, nesse caso, dizem respeito às inovações na forma de morar nos termos adiante colocados.

Em decorrência da rígida normativa urbanística protecionista, a oferta de bens imóveis no âmbito das antigas espacialidades nos 
centros históricos pode ser considerada, hoje, relativamente inelástica. Os proprietários/ locadores dos imóveis deveriam, por força da lei, conservá-los, ou seja, manter as suas qualidades arquitetônicas sem promover as ampliações de áreas construídas. Sobre essa problemática, Bernardino e Lacerda (2015) pronunciam-se afirmando que os instrumentos legais de preservação levam a supor que a vida útil do imóvel não se esgotará,

tendo em vista a obrigatoriedade da sua preservação, aliada ao fato de não ser permitido acréscimo na ocupação dos seus terrenos. Adicione-se, ainda, que nesse centro [Recife] é vetada a utilização do remanescente do terreno para a construção de edifício verticalizado, pois este prejudicaria a integridade da paisagem histórica da área de ambiência. (p. 8)

Trata-se, portanto, de um mercado com alto grau de inelasticidade por parte da oferta. Mesmo que se pudesse ampliar a oferta residencial desses bens, por meio da "reativação" ou da reabilitação de imóveis e domicílios vagos, não há indicativos de que exista, hoje, o interesse para tal por parte dos principais agentes que atuam nesse mercado residencial enquanto promotores-ofertantes. Existem, assim, duas opções para esses proprietários locadores: ruína ou reforma. Naquelas partes dos centros históricos onde persiste o uso habitacional, a ausência de políticas específicas tem conduzido muitos bens patrimoniais à ruína. Naquelas partes com fortes incentivos à instalação de empresas, a exemplo do bairro do Recife e de Santo Antônio, o uso habitacional foi praticamente erradicado. No caso de imóveis com grandes terrenos que podem comportar o estacionamento de veículos, em muitos casos, o uso habitacional também cede lugar para os usos comerciais e de serviços.

Em contrapartida, no mercado de unidades habitacionais novas, fora das áreas protegidas, graças à disponibilização de crédito à produção e à comercialização e à existência de muitos terrenos e lotes com estruturas de fácil substituição, além de numerosos lotes que podem ser remembrados para abrigar novos ciclos de produção residencial, a reprodução do capital tem se singularizado pelo elevado volume de recursos financeiros em um único empreendimento, tão elevado que, em muitos casos, exige a formação de consórcios imobiliários. Isso tem sido possível graças à legislação urbanística. Esta, ao permitir - em largas extensões territoriais da cidade, incluindo o entorno do seu centro histórico - remembramentos de terrenos e elevados coeficientes de utilização do solo, confere à oferta uma forte elasticidade, além de elevado grau de liberdade na definição do produto em termos programáticos (número de cômodos e garagens, áreas de lazer...). Está-se, pois, diante de um mercado com elevado grau de elasticidade da oferta e "pautado na 'negação', na 'desconstrução' do centro histórico enquanto lugar de moradia" (ibid., p. 62). Ademais, os promotores imobiliários revelam grande interesse em dar continuidade aos empreendimentos planejados para a área. Embora haja um consenso entre os empresários do setor que o momento atual é de "crise" e de "retração", eles não deixam de caminhar os processos burocráticos de aprovação dos grandes empreendimentos na área ${ }^{11}$ (Bernardino, 2018). 
Para além do nível de elasticidade da oferta, outros aspectos distinguem o mercado no âmbito das antigas e novas espacialidades, o nível e o grau de informação que detêm os agentes.

Quanto aos agentes que atuam no mercado imobiliário de aluguel nos centros históricos, pode-se afirmar que os proprietários/ locadores (pessoas físicas e jurídicas) são significativamente mais numerosos do que os vendedores, ou seja, as empresas incorporadoras de unidades habitacionais novas. Em relação às unidades residenciais novas, mais especificamente às localizadas no entorno desse centro, embora haja várias empresas incorporadoras atuando, praticamente a metade das unidades ali produzidas, a partir dos anos 2000, é colocada no mercado pela atuação de uma empresa, em sua figura jurídica ou na figura do consórcio imobiliário da qual faz parte. Esse empreendimento, em suas linhas centrais, expressa uma enorme economia de escala, influenciando a demanda e os preços por meio da diferenciação de produtos ofertados, ou seja, da viabilização de uma nova "forma de morar".

Quanto à demanda, ela é numerosa no mercado tanto de bens secundários habitacionais, localizados nos centros históricos, como de unidades habitacionais novas no seu entorno. $O$ que muda é o perfil da demanda. No caso recifense, de acordo com o Censo de 2010, apenas $10 \%$ dos residentes no $\mathrm{CHR}$ recebiam mais de 5 salários mínimos. Enquanto isso, no seu entorno, os que recebiam acima disso representavam $19 \%$.

No que se refere ao grau de informação, os proprietários/locadores e inquilinos de imóveis antigos mantêm praticamente o mesmo nível de informação. Na atualidade, eles dispõem de sites especializados ou então procuram se informar dos preços históricos praticados na localidade onde desejam ofertar unidades habitacionais. Não ocorre o mesmo no caso de compradores e vendedores de unidades novas. A diferença reside no fato de os incorporadores serem comparativamente mais bem informados do que os adquirentes quando o assunto é saber, com antecedência, quais os possíveis investimentos públicos e privados a serem realizados nas áreas de interesse do setor imobiliário habitacional. Ademais, eles são organizados. Contam, no caso recifense, com o apoio da Associação da Empresas do Mercado Imobiliário (Ademi-PE). Esta, além de realizar sistematicamente, pesquisas de mercado capazes de indicar a velocidade de venda dos produtos consoante à localização (bairro), pressionam os poderes executivo e legislativo no que se refere ao conteúdo das normativas de uso e ocupação do solo. 0 acesso privilegiado às informações configura-se como um elemento de monopólio.

Em suma, no caso das antigas espacialidades, os agentes ofertantes e consumidores possuem graus de informação e capacidade de interferência sobre os mecanismos de funcionamento do mercado semelhantes: pouco conhecem sobre a dinâmica do mercado imobiliário residencial na área central como um todo e praticamente não têm capacidade de interferir sobre a lógica de seu funcionamento; também apresentam um baixo nível de organização, sendo escassas as instâncias para discussão dos seus possíveis interesses e objetivos comuns. ${ }^{12}$

No caso das novas espacialidades, existe uma grande disparidade nos graus de informação que detêm os agentes ofertantes (vendedores) e consumidores (compradores), 
o que interfere nas suas respectivas capacidades de interferência sobre os mecanismos de funcionamento do mercado. Os promotores imobiliários, além de encontrarem meios de se fazerem representar em múltiplas discussões técnicas no âmbito dos conselhos de participação social instituídos, encontram, ainda, outros meios de influenciar e interferir nos rumos da política urbana. Os consumidores das novas espacialidades residenciais, por sua vez, demonstram um baixo nível de organização e pouco conhecimento sobre a dinâmica do mercado para além das suas "expectativas de consumo".

Bernardino (2018), ao estabelecer uma comparação entre os consumidores de imóveis no âmbito das antigas e das novas espacialidades, ressalta que é possível inferir que os primeiros têm, em muitos casos, um comportamento distintivo já que, a depender da idade e do estado de conservação dos imóveis, fazer uma opção de consumo residencial por um imóvel "mais antigo" pressupõe a realização de reformas e obras de manutenção. Já os consumidores das novas espacialidades residenciais parecem por vezes responder diretamente a um estímulo de consumo viabilizado por aquelas estratégias mercadológicas que lastreiam as inovações de localização e dos produtos imobiliários.

Em todo caso, no mercado imobiliário nos centros históricos, os agentes (proprietários/locadores e inquilinos) são numerosos ao ponto de não interferirem, isoladamente, no mercado. Esses detêm conhecimento da disponibilidade dos bens e dos preços ofertados, com quase nula possibilidade de economia de escala por conta das normativas protecionistas. Têm-se, portanto, numerosos elementos de concorrência perfeita. No entanto, como os produtos são heterogêneos, o monopólio de cada locador em relação ao seu próprio bem imobiliário (localização, estado de conservação, qualidade do espaço público onde se localiza, etc.) interfere no funcionamento do mercado. Isso quer dizer que esse mercado funciona a partir de um modelo de concorrência imperfeita, mais precisamente de concorrência monopolista, na medida em que comporta elementos de concorrência perfeita e de monopólio.

Pode-se concluir, ainda, que o mercado imobiliário de unidades novas também funciona a partir de um modelo de concorrência imperfeita, mais especificamente de um modelo oligopolista. Afinal, as empresas maiores e mais bem sucedidas buscam constantemente vantagens competitivas de várias formas: (1) acessando, a custos menores, as matérias-primas; (2) lançando novos produtos; (3) influenciando a demanda por meio da publicidade; (4) organizando-se enquanto segmento empresarial (Ademi); (5) detendo um elevado nível de informações sobre o mercado; e (6) realizando consórcios para viabilizar grandes empreendimentos, o que significa importante economia de escala, além de indicar um potencial de dominar espacialmente o mercado (concentração da produção). Convém anotar que, de todas essas vantagens competitivas, a mais poderosa arma da concorrência é a inovação, seja na oferta de novas formas de morar, seja na tecnologia de produzir, seja na viabilização de megaproduções (consórcios de empresas).

Assim, tanto no mercado imobiliário de aluguel nos centros históricos, quanto no mercado de compra e venda das novas espacialidades residenciais nas áreas do entorno, não se pode dizer que haja a conformação 
de uma concorrência perfeita. A concorrência é imperfeita nos dois casos, mas por motivos diferentes. No caso das antigas espacialidades, a concorrência é imperfeita por se configurar uma concorrência monopolística nos termos de Chamberlain (1933, apud Lacerda, 2018). Dada à heterogeneidade dos bens transacionados, uma vez que estes foram "produzidos em épocas diferentes, em condi-ções de produção e de circulação diferentes e situados em diversas áreas (qualitati-vamente diferenciadas)", eles podem ser considerados únicos (Lacerda, 2018). Como bens únicos, durante as transações imobiliárias, os seus mecanismos de fixação do preço se baseiam na disponibilidade e na capacidade de pagamento do consumidor, fato que configura uma situação de "monopólio, no caso, locacional, praticado pelos proprietários dos imóveis". Como relata a autora,

Em 1933, Edward Chamberlain, no seu trabalho A teoria da concorrência monopolista, foi um dos primeiros economistas a lançar a hipótese da concorrência monopolista. Ele adotou como centro da sua análise o mercado de compra e venda. Um dos pontos fundamentais do modelo de concorrência monopolística reside nas condições da demanda. Para ele [Edward Chamberlain], a diferenciação dos produtos induz os consumidores a escolherem o de um determinado vendedor, o que confere à oferta a capacidade de exercer certo controle sobre os preços. Daí que diferentes vendedores ou locadores obterão preços diversos, segundo o julgamento dos consumidores, em relação às qualidades comparativas dos produtos diferenciados, notadamente no que toca à localização. (Ibid., pp. 14-15)
Edward Chamberlin foi o primeiro economista a reconhecer, ainda na década de 1930, a concorrência monopolista, enquanto estrutura de determinados mercados. Inserido nessa estrutura, cada vendedor, no caso em pauta o locador, tem o monopólio do produto, mas fica sujeito à concorrência de produtos substitutos, mais ou menos imperfeitos. A despeito de inserido em um contexto histórico e empírico bem específico, esse economista se sobressaiu pela capacidade de identificar traços gerais do mercado fundiário urbano como de concorrência monopolista. Não se trata aqui de aderir a uma teoria atemporal e universal, mas de entender o geral para daí compreender as particularidades e as mudanças concretas nos modos de organização dos diversos tipos de mercado imobiliário.

A concorrência monopolista é acentuada quando se trata de um imóvel histórico, já que a condição de irreprodutibilidade do bem é notável. Já, no caso das novas espacialidades, a concorrência é imperfeita, pois, embora os bens sejam relativamente menos heterogêneos e a demanda possa ser caracterizada pelo elevado número de agentes, a presença de poucos promotores-ofertantes concentrando parte significativa da produção permite afirmar que se está diante de um modelo de mercado oligopolista, já que a saída de um desses ofertantes pode alterar substancialmente o funcionamento do mercado.

O Quadro 1 distingue as diferenciações de funcionamento do mercado habitacional de aluguel nos centros históricos, no confronto com o modelo de compra e venda de unidades habitacionais novas nas suas áreas circundantes. Mais ainda, examina o quanto a dinâmica 
desses dois mercados é tributária da disponibilidade de crédito. Tal disponibilidade, como será visto, impulsiona os agentes desses dois mercados a agirem de forma radicalmente diferenciada e, portanto, com efeitos espacialmente opostos.

\section{Quadro 1 - Distinções entre o mercado imobiliário em centros históricos e o mercado de novas unidades no seu entorno - 2018}

\begin{tabular}{|c|c|c|}
\hline Aspectos relevantes & $\begin{array}{l}\text { Mercado imobiliário } \\
\text { em centros históricos }\end{array}$ & $\begin{array}{c}\text { Mercado imobiliário } \\
\text { de novas unidades no entorno }\end{array}$ \\
\hline $\begin{array}{l}\text { Transação imobiliária } \\
\text { predominante }\end{array}$ & $\begin{array}{l}\text { Aluguel - imóveis usados mais ou menos } \\
\text { antigos. }\end{array}$ & $\begin{array}{l}\text { Compra e venda de imóveis novos e/ou } \\
\text { inconclusos }\end{array}$ \\
\hline $\begin{array}{l}\text { Composição do estoque } \\
\text { ofertado }\end{array}$ & $\begin{array}{l}\text { Bens heterogêneos - casas, cômodos, } \\
\text { apartamentos em edificações de até } \\
8 \text { pavimentos, em diferentes estilos } \\
\text { arquitetônicos e em diversos estados de } \\
\text { conservação. }\end{array}$ & $\begin{array}{l}\text { Bens pouco diversificados } \\
\text { (apartamentos), em edificações de } 20 \text { a } \\
50 \text { pavimentos, com múltiplas unidades } \\
\text { habitacionais. }\end{array}$ \\
\hline Normas urbanísticas & $\begin{array}{l}\text { Normas restritivas às mudanças } \\
\text { morfotipológicas, o que dificulta } \\
\text { a adaptação dos imóveis às novas } \\
\text { necessidades habitacionais. }\end{array}$ & $\begin{array}{l}\text { Normas urbanísticas de incentivo à } \\
\text { construção verticalizada, com altos } \\
\text { coeficientes de aproveitamento. }\end{array}$ \\
\hline Políticas habitacionais & $\begin{array}{l}\text { Políticas públicas de incentivo à } \\
\text { manutenção do uso habitacional } \\
\text { inexistentes ou de alcance reduzido. }\end{array}$ & $\begin{array}{l}\text { Políticas públicas de incentivo à produção } \\
\text { e à comercialização de unidades } \\
\text { habitacionais a partir dos anos } 2000 \text {. }\end{array}$ \\
\hline Oferta & $\begin{array}{l}\text { Oferta praticamente inelástica: não } \\
\text { interesse dos agentes imobiliários } \\
\text { na reabilitação de imóveis para fins } \\
\text { habitacionais. }\end{array}$ & $\begin{array}{l}\text { Forte elasticidade da oferta: normas } \\
\text { urbanísticas favoráveis, políticas públicas } \\
\text { habitacionais, disponibilidade de terrenos } \\
\text { e interesse dos produtores imobiliários. }\end{array}$ \\
\hline Perfil dos ofertantes & Muitos proprietários/locadores. & Poucas incorporadoras/construtoras. \\
\hline Perfil dos consumidores & $\begin{array}{l}\text { Muitos inquilinos com baixo e médio } \\
\text { poder aquisitivo. }\end{array}$ & $\begin{array}{l}\text { Muitos inquilinos com médio e alto } \\
\text { poder aquisitivo. }\end{array}$ \\
\hline Grau de informação & $\begin{array}{l}\text { Proprietários/locadores e inquilinos } \\
\text { mantêm praticamente o mesmo nível } \\
\text { de informação. }\end{array}$ & $\begin{array}{l}\text { Ofertantes e consumidores com } \\
\text { disparidade quanto à informação. }\end{array}$ \\
\hline $\begin{array}{l}\text { Comportamento } \\
\text { dos agentes }\end{array}$ & $\begin{array}{l}\text { Agentes "passivos" e dispersos, com } \\
\text { pouca capacidade de articulação e } \\
\text { interferência sobre os mecanismos } \\
\text { de funcionamento do mercado. } \\
\text { Proprietários/locadores não } \\
\text { schumpeterianos: destruição não } \\
\text { criativa. }\end{array}$ & $\begin{array}{l}\text { Agentes ativos, articulados e organizados, } \\
\text { com capacidade de interferência sobre } \\
\text { os mecanismos de funcionamento do } \\
\text { mercado. Empresário schumpeterianos: } \\
\text { criação de novas espacialidades }\end{array}$ \\
\hline $\begin{array}{l}\text { Modelo de funcionamento } \\
\text { do mercado }\end{array}$ & $\begin{array}{l}\text { Concorrência imperfeita: } \\
\text { concorrência monopolística. }\end{array}$ & $\begin{array}{l}\text { Concorrência imperfeita: } \\
\text { concorrência oligopolista. }\end{array}$ \\
\hline
\end{tabular}

Fonte: as autoras. 


\section{Apontamentos conclusivos}

Os proprietários/locadores de imóveis para aluguel habitacional nos centros históricos não vêm se comportando como empresários schumpeterianos. Sem dúvida, as normas protecionistas impedem que sejam impulsionados pela destruição criativa. Assim fazendo, eles não vêm adotando inovações na forma de morar. Em extensão, vêm contribuindo para a reprodução das espacialidades preexistentes, nas quais se situam os seus imóveis. Dito de outra forma: sem políticas de incentivos à recuperação/reabilitação dessas localidades, muitos deles adotaram e continuam a adotar uma postura que, em suas linhas centrais, vem significando uma destruição não criativa, isto é, um estrago, muitas vezes irreversível, dos bens patrimoniais.

Naquelas partes com fortes incentivos à instalação de empresas - como tem se observado nos bairros do Recife e de Santo Antônio, no Centro Histórico do Recife -, o uso habitacional vem sendo praticamente abolido. Nesse caso, não se trata das tradicionais empresas do mercado imobiliário de unidades habitacionais novas, mas de empresas do moderno setor comercial e de serviços. Esse retorno, como salientado introdutoriamente, vem acontecendo no $\mathrm{CHR}$, sob o comando do setor público (recuperação/dotação de infraestruturas, incentivos fiscais, políticas setoriais, etc.), e tem impulsionado os agentes a reinventar o mercado imobiliário nessa localidade, por meio de ações que conduzem a uma conservação inovadora, nos termos propostos por Lacerda (2018). Através dos incentivos governamentais, esses agentes inovam por meio da conservação dos bens patrimoniais. Isso significa modernizá-los, tornando-os aptos a abrigar atividades contemporâneas do setor comercial e de serviços. Isso, muitas vezes, ao custo do aniquilamento de parte substantiva do uso habitacional.

Pelo exposto no decorrer deste texto, pode-se afirmar que a dinâmica de ressemantização de áreas urbanas centrais das cidades brasileiras não vem significando o resgate da habitablidade dos seus respectivos centros históricos, onde predomina o mercado de aluguel de moradias usadas. Ademais, pode-se asseverar que esse mercado pouco se articula à dinâmica de produção de novas espacialidades residenciais nos seus respectivos entornos, 0 que resulta em mercados diferentes, com baixo nível de comparabilidade.

Para finalizar, cabe anotar que, apesar da queda dos investimentos a partir de 2013, devido à crise da economia brasileira, esse setor passou a deter, nesses entornos, uma expressiva reserva fundiária, suporte para a retomada dos investimentos numa conjuntura econômica mais favorável. 


\section{[I] https://orcid.org/0000-0003-3596-1736}

Universidade Federal de Pernambuco, Programa de Pós-Graduação em Desenvolvimento Urbano, Departamento de Arquitetura e Urbanismo. Recife, PE/Brasil.

norma_lac@yahoo.com.br

\section{[II] https://orcid.org/0000-0002-4256-8505}

Universidade Federal de Pernambuco, Centro de Artes e Comunicação, Departamento de Arquitetura e Urbanismo. Recife, PE/Brasil.

ianaludermir@gmail.com

\section{Notas}

(1) Com dotação de recursos também do BID - Banco Interamericano de Desenvolvimento.

(2) O Plano Diretor atualmente vigente foi revisado e a minuta da lei do novo Plano Diretor se encontra em discussão na Câmara de Vereadores do Recife desde o segundo semestre de 2018.

(3) Três dos empreendimentos finalizados tem Habite-se de 2009 e um tem Habite-se de 2017.

(4) Considerando a densidade de habitantes por domicílio da RPA1 de 2,67 (IBGE, 2010), multiplicou-se o número de unidades habitacionais novas pela densidade de moradores por domicílio, chegando-se a 7.596,15 novos habitantes.

(5) A RPA1, como foi dito, apresentava 78.098 habitantes em 2000 e 78.114 habitantes em 2010, o que significa um crescimento populacional de 16 habitantes em 10 anos.

(6) Alvarás de Construção (variam de 2006 a 2015) e Habite-se (variam de 2009 a 2017) no http:// licenciamento.recife.pe.gov.br/sites/all/selurb-serv/licenciamentoFiscalizacao.php

(7) O Consórcio Novo Recife e o Grupo JCPM são responsáveis, respectivamente, pelos projetos Novo Recife e Largo dos Casados (empreendimentos mistos - empresarial/comercial/serviços e habitacional), em distintas fases de licenciamento e discussão junto ao poder público municipal.

(8) Três dessas empresas têm/tiveram atuação em outros estados do Nordeste.

(9) Por não estarem oficialmente aprovadas ou com empreendimentos "Iançados", como é o caso daquelas que remetem aos empreendimentos do Grupo JCPM

(10) Esse número refere-se apenas a unidades lançadas por grandes construtoras afiliadas da Ademi, podendo existir empreendimentos de menor porte, de ouras construtoras, que não constam nesse levantamento.

(11) Como é o caso do Projeto Novo Recife, do Consórcio Novo Recife, e do Projeto Largo dos Casados, do Grupo JCPM.

(12) Associações de moradores como a "Amigos da Aurora", com moradores da Rua da Aurora, reúnem moradores das antigas e novas espacialidades, e promovem ações e eventos no espaço público, pleiteiam a permanência ou a saída de comerciantes ambulantes, pleiteiam a melhoria de alguns aspectos da orla da Rua da Aurora. Considera-se essa uma atuação muito limitada. 


\section{Referências}

ABRAMO, P. (1995). A regulação urbana e o regime urbano: a estrutura urbana, sua reprodutibilidade e o capital. Ensaios FEE. Porto Alegre, v. 16, pp. 510-555.

(2007). A cidade com-fusa. A mão inoxidável do mercado e a produção da estrutura urbana nas grandes metrópoles latino-americanas. Revista Brasileira de Estudos Urbanos e Regionais, v. 9, n. 2 .

BERNARDINO, I. (2018). Mercado imobiliário residencial em áreas centrais tradicionais: produção de novas espacialidades e obsolescência imobiliária na definição de submercados residenciais. Tese de doutorado. Recife, Universidade Federal de Pernambuco.

BERNARDINO, I. L.; LACERDA, N. (2015). Centros históricos brasileiros: tensões entre a obsolescência imobiliária e a construção de novas espacialidades. Revista Brasileira de Estudos Urbanos e Regionais, v. 17, n. 1, pp. 61-74. Disponível em: http://www.anpur.org.br/publicacao/ arquivos/20160517100357. Acesso: 2 fev 2018.

CHAMBERLAIN, E. (1953). La théorie de la concurrance monopoliste. Paris, Presses Universitaires de France.

FERNANDES. A. C.; LACERDA, N. (2019). Em que cesta colocar os ovos: a peleja do Porto Digital entre promoção de software e valorização do Recife Antigo. In: ENANPUR XVIII, Anais.... Natal.

LACERDA, N. (1993). La production sociale des interêts fonciers et immobiliers: le cas de Recife (Brésil). Tese de Doutorado. Paris, Universite de la Sorbonne Nouvelle - Paris III

(2018). Mercado imobiliário de bens patrimoniais: um modelo interpretativo a partir do centro histórico do Recife (Brasil). EURE, v. 44, n. 132, pp. 113-132.

SCHUMPETER, J. (2012). Teoria do desenvolvimento econômico. Uma investigação sobre lucros, capital, crédito, juro e o ciclo econômico. Lisboa, Fundação Calouste Gulbenkian.

SMITH, N. (2003). "La gentrification généralisée: d'une anomalie local à la "régénération" urbaine comme stratégie urbaine globale". In: BIDOU-ZACHARIASEN, C. (org.). Retours en Ville. Paris, Descartes \& Cie.

Texto recebido em 14/out/2019

Texto aprovado em 30/mar/2020 